\title{
Interview with Tamara Moats, Speaker on Visual Thinking and Use of Art Data
}

\author{
By Cybèle Elaine Werts, Article Editor of Education Libraries
}

NOTE: I met Tamara Moats when she was on a panel at the Special Libraries Conference in Seattle, WA this June. Her lecture/demonstration was entitled Visual Thinking and Use of Art Data. As I knew of our upcoming issue on digital, information, and visual literacy, I contacted her right away for an interview as a special addition to this issue.

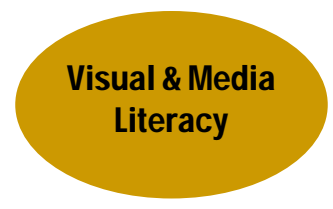

Tamara Moats was curator of education at the University of Washington's Henry Art Gallery for nineteen years where she organized programs for all ages, developed the museum's teaching methods, and wrote extensive curricula. She now teaches art history at the Bush School Upper School and the Cornish College of the Arts, and visual thinking at the University of Washington Medical School. Moats holds a BA degree in art history from the University of Puget Sound and an MA in Asian Studies from the Claremont Graduate School.

\section{To help explain Tamara's work, I've included this explanation of Visual Thinking:}

Visual Thinking is an inquiry-based method of teaching with original art works. It empowers viewers to trust their own observations, interpretations, and ideas about works of art. Facilitators ask students to articulate their responses and to find evidence to support opinions and reasoning. Student response drives all observations; the facilitator does not direct the discussion.

Visual Thinking focuses on viewer response and interest. Using dialogue posed by the teacher or exhibition guide, Visual Thinking allows the viewer to guide the inquiry. In this sense it is not informationbased, but information is woven into the discussion as it is asked for. The process progresses from narrative artwork to more complex ones, exploring images that relate to but play off of each other. Questioning begins very simply by asking students "What is going in this artwork?" and allowing the discussion to follow a logical but creative progression. The idea is to reveal information about the work throughout the discussion, and guide the questioning to places that illuminate the artwork. This includes exploring composition, subject matter, medium, and artist, but the stress is placed on discovering meaning and deeper ideas. Visual Thinking builds critical and creative thinking skills that enhance the whole of the aesthetic experience.

One of the things that strikes me first about your unusual vocation is that most viewers probably say that they don't know anything about art, and therefore their thoughts and observations about it cannot possibly have value. How do you counter this widespread idea that only experts can understand art?

My belief is that if under open and welcoming circumstances, most people cannot help but give their responses to an artwork, and if the works are well chosen, find something to talk about. The adult audience is a little more tricky, since older people usually do want to get some background before responding, but I have found that with the right, very brief, introduction, I can ask a question that the audience wants to answer. As for children, it is the reverse: all kids want to tell you what they see before getting any information on an artwork. They need little encouragement. 
The traditional view of teaching art is through lecturing, but clearly that is no longer considered effective. Why do you think this change in approach has occurred? What is the thinking behind waiting until students "ask" for information - like when the artwork was painted - before offering it?

Lecturing only reaches a small group of learners, and is especially unhelpful in the museum setting, where a group is visiting for the average of an hour. From almost the beginning of my museum career, I could see that talking too much put people off, and really hampered the aesthetic experience. The Visual Thinking process (VTS) is dynamic and interesting, and builds off of people's responses. All of this is a more pleasurable process of looking and learning, and one where information is retained. When you wait for a student/visitor to ask for information, you have found the teachable moment, and the information makes sense to them.

One aspect of the Visual Thinking Process is that it is "inquiry-based" which is a concept that is used in other teaching areas such as science. For example, students often find personal explorations of nature far more useful than

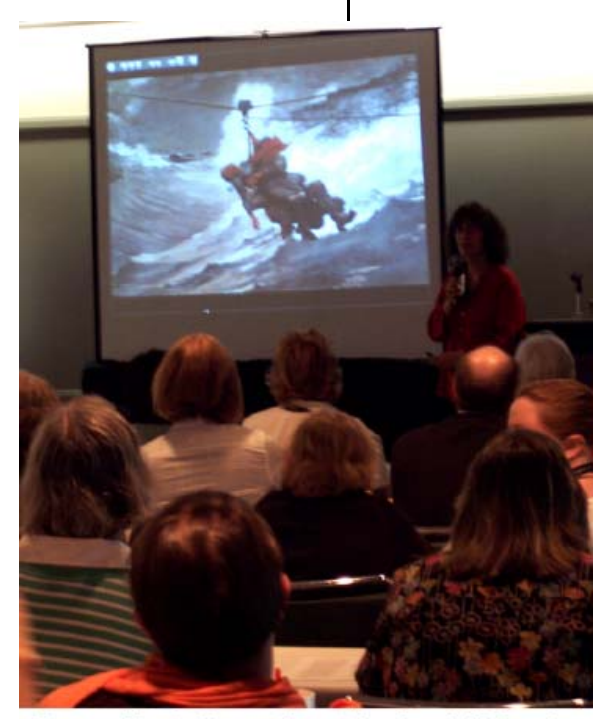

Tamara Moats Presenting at the Special Libraries Association Workshop on Visual Thinking. Seattle Conference, June 2008
This is difficult to put into words, but basically, you allow them to do what they can do. You choose works that are stimulating to talk about, and that progress in challenge. You ask for as much detail as possible, and make them look, and then look again. As they have success in unlocking the mysteries of an artwork, they want to know more, and look more. They begin to trust themselves.

Can you give me some examples of the questions you might ask me to guide me to an understanding of an artwork? Suppose you used Homer's The Lifeline, as you did in your SLA presentation.

The first VTS question is "What do you see here?" or "What is going on in this image?" Subsequent questions build off of the answers, but remain very simple. Perhaps: what colors, what lines, what shapes? Then you build off of the answers.

My understanding is that you ask the students to articulate their responses and to find evidence to support opinions and reasoning. What might be an example of evidence to support an opinion about art?

Students need to describe what they see and be articulate about the details. They need to explain their observations based on what is there, but they may also be creative about interpretation. VTS does not discourage responses, or guide the process to a given goal. There is no goal.

I imagine that you also need to explore composition, subject matter, medium, and artist. How do you teach these traditional aspects of art while you are also doing this more esoteric type of exploration? And really, how much does a teacher or librarian need to know to share art using this method with others? Do they need all the degrees and experience that you have? their intuition about what they see? How do you teach them to "see?" 
Actually, in the pure form of VTS we do not explore composition, medium or artist. Traditional aspects (formal elements) are not taught, and indeed, if students left an exhibition not knowing a single artist's name, it is okay in VTS. Thus, teachers and librarians do not need a lot of background information to use this method.

At the workshop I attended, you spoke of how students advance from being novice to more sophisticated viewers of art. What do you see and hear from them as they progress in their understanding of what they see? Can you give some examples?

As students progress they use more sophisticated vocabulary, more creative terms to describe things like color, and start to come up with unusual and complex interpretations. One student I had in the museum described a sky as pumpkin colored instead of just orange, and another made up a story that was happening off the edge of the paintingthe approach of a bear to the figure in the center. Also when students become more sophisticated they begin to ask deeper questions about the work.

Considering how open-ended the inquiry method seems to be, is it possible that viewers can have a "wrong" interpretation? Can any understanding of an artwork be truly "wrong?"

It's not true that there are no "wrong" answers - the tree is green or the sky is orange-but in general, VTS accepts all answers if the viewer can ground it in the evidence of the

painting. If the observation is still off-base, I ask the group if they see what the other viewer sees. I let them work it out. But in

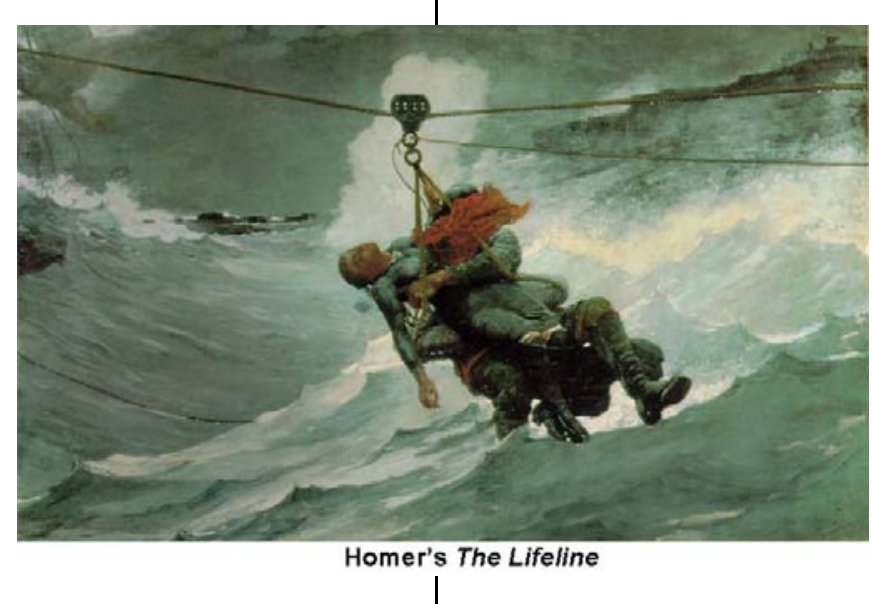
and whatever message we might gain from it. The idea of visual literacy has become important society, of a people, of an individual. It is a pathway to the soul. It stimulates us to think, even for just a few minutes, in a new way, and in that sense, open new pathways in the mind. There is an information aspect to it, which is interesting, but that is not central. It is about the experience, either sensual or rational,

get a degree to get a job. How would you say the skills of visual thinking enhance the learning process as well as our ability to move through the world?

VTS develops both critical and creative thinking skills which are essential to the learning process and applicable in all situations that involve ambiguous material. I also teach this to medical students to help them develop their diagnostic skills. I hope what I teach allows my students to see the artwork differently both visually and intellectually, and that they take this new ability out to see the world differently as well.

Most of my questions to you have focused on art, but I believe what we're talking about here is part of the broader scope of information and digital literacy. Where do you see the study of art in that continuum? How important is visual literacy really?

Given that I love art; looking at and thinking about it, I see it as something that pervades all aspects of the contemplative life. Art is a reflection of that focus on art and visual thinking is often secondary to students who are out to e

(n)


currently because we are so bombarded with imagery every waking moment. It is important to become visually literate, or visually discerning, in order to survive.

\section{There was an interesting Twitter} (http://twitter.com/ ) about your presentation at the SLA conference that said: "Tamara Moats rocks. She led us through an examination of Homer's The Lifeline. We all do have instincts to interpret what we see." Do you feel that you are, as they say, “changing lives?”

I am not so arrogant as to think I can change lives, but as a museum educator, I was trying to make the world a better place, and to help create a museum that stimulated thought as well as gave pleasure. As a teacher, I hope I have motivated a number of students to look at the world differently, and a few have decided to major in art history!

\section{Thanks very much Tamara, I enjoyed both} hearing your engaging presentation as well as chatting with you!

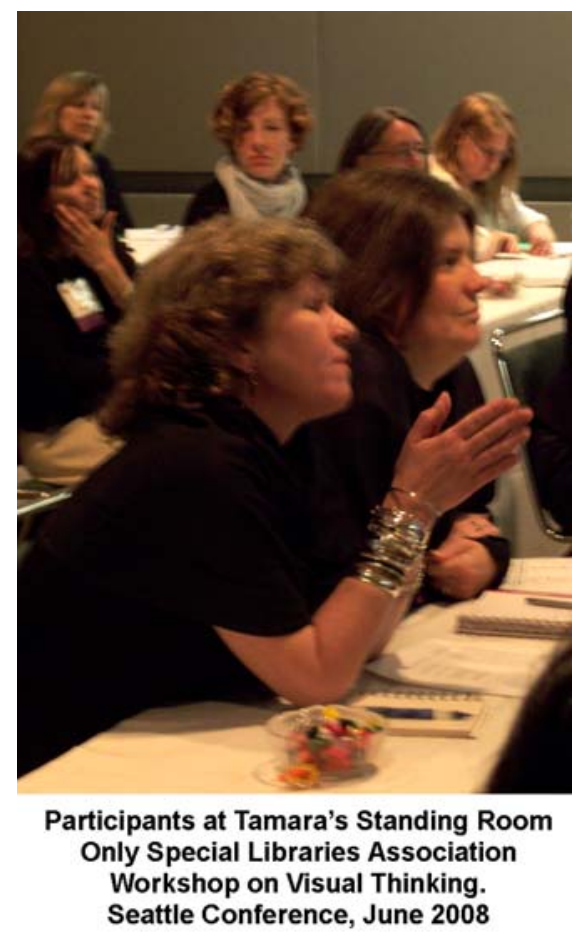

Tamara Moats can be reached at:

Tamara.Moats@bush.edu

\section{A p p l i c a t i o n $\mathbf{R}$ e v i e w}

Review of the Cuadra STAR Application for

Library Automation - Managing both Traditional and Electronic Library Collections

This is a review of the Cuadra STAR application which is used for an article level

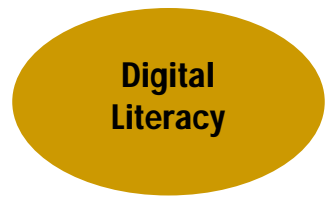
database in an historical digital collection. The review focuses on the creation of the database, input and output fields and webpage creation. The review also includes the step-by-step process used to create the collection and the pros and cons of each step. Overall, the experience with building our database and web interface in STAR was extremely positive. If one has experience with database creation and HTML, this software is ideal to use, however, STAR would benefit from some work on their user interfaces.

\section{About Cuadra STAR}

Cuadra offers a comprehensive suite of customizable, task-oriented knowledge management solutions. Each Cuadra solution is designed to meet the professional standards in its field, as well as provide for fast, precise webbased retrieval, to enable users to find the information assets they need, when they need them.

- Collections Management: for managing the full range of archive, museum, photographic, and image collections

- Library Automation: for managing both traditional and electronic library collections

- Knowledge Management: for managing the "corporate memory" - the vital information being created and acquired by your organization

- Media Management: for managing all kinds of visual collections, including those 